\title{
Natural fibres-based polymers: Part I-Mechanical analysis of Pine needles reinforced biocomposites
}

\author{
VIJAY KUMAR THAKUR and A S SINGHA* \\ Material Science Laboratory, National Institute of Technology, Hamirpur 177 005, India
}

MS received 17 April 2008

\begin{abstract}
Lack of resources and increasing environmental pollution has evoked great interest in the research of materials that are friendly to our health and environment. Polymer composites fabricated from natural fibres is currently the most promising area in polymer science. Keeping in view the various advantages of natural fibres, in current series of green composites a study on natural fibre reinforced polymer composites has been made. This paper presents the results of an experimental series designed to assess the possibility of Pine needles as reinforcing material in polymer composites. First of all, urea-formaldehyde resin was synthesized and optimized by evaluating its mechanical properties. Optimized resin was reinforced with employing Pine needles of different dimensions such as particle reinforcement, short fibre reinforcement and long fibre reinforcement. Experimental results obtained shows that mechanical properties such as tensile strength, compressive strength and wear resistance of UF resin increases to a considerable extent when reinforced with Pine needles. Further it has been observed that particle reinforcement is more effective as compared to short fibre and long fibre reinforcement. These results suggest that Pine needles can be potential candidates for use in natural fibre reinforced polymer composites. Thermal and morphological studies of these composites have also been carried out.
\end{abstract}

Keywords. Composites; reinforcements; optimization; mechanical properties; thermal study.

\section{Introduction}

With emphasis on environmental awareness and consciousness, academic and industrial needs for developing environmentally friendly composite materials have recently been increasing with significant attraction, based on renewable resources like natural fibres as alternatives for synthetic fibres in various applications such as reinforcement in traditional synthetic fibre-reinforced polymer matrix composites (Singha and Thakur 2008a, b). Moreover, natural fibre-reinforced composites come from renewable materials and can be obtained very easily. Advantages of natural fibres over usual reinforcing fibres such as glass and carbon fibres are low cost, low density, high toughness, acceptable specific strength, enhanced energy recovery, recyclability, biodegradability etc (Gassan and Bledzki 1997; Bledzki and Gassan 1999; Chakraborty et al 2006; Singha et al 2008a, b). It has been observed that natural fibres such as flax, sisal, Hibiscus sabdariffa, and Grewia optiva etc on reinforcement improved the mechanical properties of polymer composites (Bledzki and Gassan 1999; Mao et al 2000; Kaith and Kalia 2007). These natural fillers are not only

*Author for correspondence (assingha@gmail.com) inexpensive but also able to minimize the environmental pollution enabling these composites to play an important role in resolving future environmental problems (Misra et al 1996; Hornsby et al 1997; Chauhan et al 2000, 2001; Kaith and Kalia 2007). As a result, research is going on to develop composites using waste biomass (Joshi et al 2004; Mathew et al 2006; Singha and Thakur 2008a, b), especially in developing composites using most environmentally friendly agro-wastes (lignocellulose materials) as reinforcing fillers and polymers as matrices.

\subsection{Natural fibres}

The properties of natural fibres mainly depend upon its chemical composition (Bledzki and Gassan 1999; Chauhan et al 2000, 2001; Singha et al 2002, 2006). Chemical composition of fibres depend on various factors. It varies with the geographic location, climate, type of fibre, plant part and soil conditions etc. Natural fibre consists of carbohydrates, lignin, and extraneous components. Carbohydrate portion of fibre comprises cellulose, hemicelluloses etc. Natural fibres along with wood fibre and other plant fibres composed of a large percentage of cellulose, making cellulose the most abundant natural polymer. The repeating unit of cellulose is the cellobiose unit which consists of two $\beta$-D1,4-glucopyranose units. Cellu- 
lose is principally responsible for strength of natural fibre because of its specific properties such as high degree of polymerization and linear orientation. Mechanical properties of these fibres are dependent on the cellulose content in the fibre, the degree of polymerization of the cellulose and the micro fibril angle. Fibres with higher cellulose content, higher degree of polymerization and a lower microfibrillar angle exhibit higher tensile strength and modulus. These fibres exhibit variations in mechanical properties both along the length of an individual fibre and between fibres. Hemicelluloses act as a matrix for the cellulose. It is supposed to act as a link between the fibrous cellulose and the amorphous lignin. Lignin is a phenolic compound that holds the fibres together. Lignin acts as a stiffening agent for the cellulose molecules within the fibre cell walls. All three cell wall components contribute in different extents to the strength of fibre.

\subsection{Matrix}

Matrix is a material which encapsulates two or more than two components in itself. In case of natural fibrereinforced composite material, matrix binds the fibres together. It transfers applied load to these fibres and also protects these fibres from harmful environmental effects. Various types of materials are generally used as matrix material such as metal matrix, ceramic matrix, carbon graphite matrix, glass matrix and polymer matrix. Among these, polymer matrices are currently being used to a larger extent because of their enormous advantages (Ray et al 2001; Nakagaito and Yano 2004, 2005; Majumdar and Adhikari 2005; Panthapulakkal et al 2006). The requirements for the matrix in Pine needle reinforced polymer composite are: (i) to bind the fibres together, and protect their surfaces from damage during fabrication in the service of life of the composite, (ii) melting point should be lower than the degradation temperature of the fibres, (iii) to keep the fibres dispersed and separated so as to avoid any catastrophic propagation of cracks and subsequent failure, (iv) to transfer stresses to the fibres efficiently by adhesion and/or friction, when the composite is under load, (v) to be thermally compatible with the reinforcement and (vi) to be chemically compatible with the fibres over a long period.

Common methods for manufacturing natural fibre reinforced polymer composites are compression molding and extrusion (Bledzki and Gassan 1999; Singha and Thakur 2008a, b). Himachal Pradesh is the hilliest state in India. Pine trees are abundantly found in Himachal Pradesh. Pine needles are the main cause of fire during summer season when trees shed their needles. This article examines the feasibility of raw Pine needle as reinforcing material for producing Pine needle reinforced polymer composites.

\section{Experimental}

\subsection{Materials and methods}

2.1a Matrix polymer: Urea, formaldehyde solution and sodium hydroxide were kindly supplied by Qualigens Chemicals Ltd. and were used as received. Resin synthesized from urea and formaldehyde was used as matrix polymer.

2.1b Reinforcing filler: The ligno-cellulosic material used as the reinforcing filler in the composite was Pine needles collected from NIT Campus Hamirpur (HP). The fibres were washed thoroughly with distilled water and dried in an air oven at $70^{\circ} \mathrm{C}$ for $12 \mathrm{~h}$ and in vacuum oven at $63^{\circ} \mathrm{C}$ for $3 \mathrm{~h}$ before preparation of composites. This fibre was used in three forms as shown here: (i) Particle reinforcement: Pine needles were grinded to a powder and filtered through a sieve of pore size, $200 \mu \mathrm{m}$, (ii) Short-fibre reinforcement: Pine needles were chopped into $3 \mathrm{~mm}$ size. This fibre was used as short fibre and (iii) Long fibre reinforcement: Pine needles were chopped into $6 \mathrm{~mm}$ size. This fibre was used as long fibre.

\subsection{Instruments used}

Weights of the samples were taken on Shimadzu make electronic balance (LIBROR AEG-220). Curing of different samples prepared was done on compression molding machine (SANTECH INDIA Ltd). Testing of samples for tensile and compressive strengths were done on Computerized Universal Testing Machine (HOUNSFIELD $\mathrm{H} 25 \mathrm{KS}$ ) and wear testing was done on Wear \& Friction Monitor (DUCOM-TR-20L). Morphological (SEM micrograph) and thermal studies (TGA/DTA, DTG) were carried out on LEO 435VP make SEM and on TGA machine LINSEIS, L 81-11 make, respectively.

\subsection{Synthesis of urea-formaldehyde resin}

Urea-formaldehyde resin was synthesized by the standard method developed in our laboratory described somewhere else (Singha and Thakur 2008b). The resin samples were then cured at $130^{\circ} \mathrm{C}$ in compression molding machine. The cured samples were then subjected to various mechanical, thermal and morphological studies.

\subsection{Mechanism of polymerization reaction}

The polymerization reaction between urea and formaldehyde is supposed to take place in two steps (Singha and Thakur 2008b). First step involves the reaction between urea and formaldehyde to form methylol urea. Since urea is tetra functional, initial reaction may lead to the forma- 


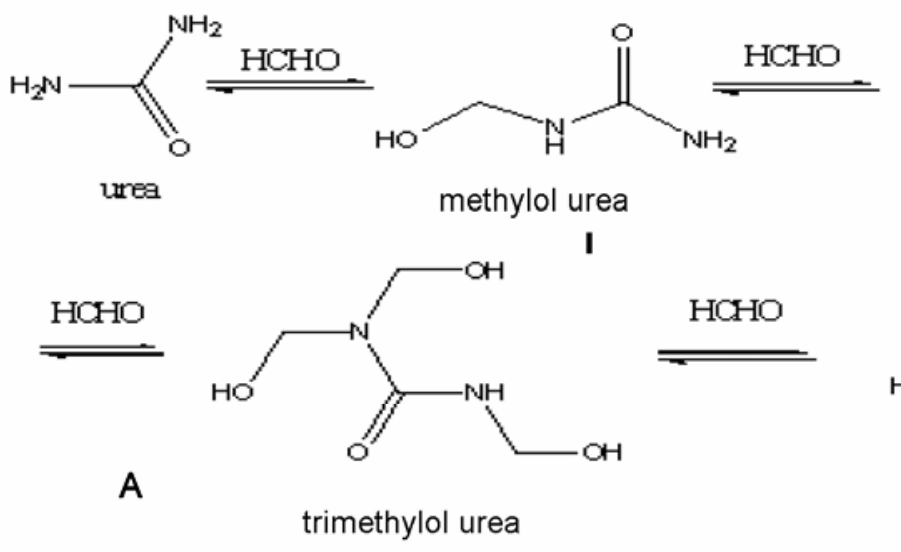<smiles>NC(=O)N(CO)CO</smiles><smiles>CN[I-]C(=O)NC</smiles><smiles>CNC(O)C(=O)NCCO</smiles><smiles>CCNC(C)=O</smiles>

B

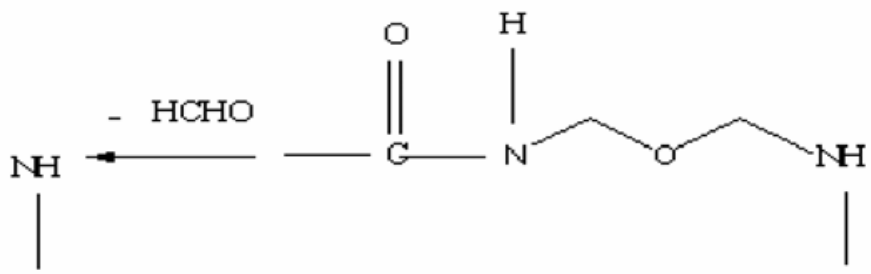

IV

Figure 1. (A) Formation of methylol derivatives of urea and (B) condensation of methylol urea by elimination.

tion of tetra methylol derivative of urea (as shown in figure $1 \mathrm{~A})$. However, slightly alkaline medium $(\mathrm{pH}$ of $7-8)$ control the reaction and favour the formation of dimethylol urea. Since these methylol ureas are non adhesive in nature so condensation does not take place. However, the condensation takes place in acidic medium. Therefore, the reaction is carried out at $80-90^{\circ} \mathrm{C}$ and reaction speed is controlled by the acidity of the medium (pH 5.5-6). As the reaction proceeds larger molecules with cross linked structures are formed. At the requisite level, the reaction is arrested by neutralization ( $\mathrm{pH} 7 \cdot 5-8)$. The condensation is closely watched and controlled at the stages of production because if the reaction is allowed to continue, cross-linking may lead to gelatization of the resin. Under acidic conditions, methylol urea condenses by elimination of water between either of four steps (as shown in figure 1B).

\subsection{Synthesis of polymer biocomposites}

Natural fibre reinforced composites were prepared by utilizing Pine needles in three different forms as discussed below: 2.5a Particle reinforced composites: Pine needles grinded to a powder of pore size, $200 \mu \mathrm{m}$, were mixed with specific amount of resin by suitable loading $(1: 0 \cdot 1)$. Curing of samples was done in compression molding machine at $130^{\circ} \mathrm{C}$ and were further subjected to different studies.

2.5b Short-fibre reinforced composites: Pine needles were chopped into $3 \mathrm{~mm}$ size and mixed with the known weight of UF resin. After proper mixing the curing of samples was carried out at $130^{\circ} \mathrm{C}$ in compression molding machine.

2.5c Long fibre reinforced composites: Pine needles were chopped into $6 \mathrm{~mm}$ length and mixed with weighed amount of resin. Curing of samples was done as described above.

\subsection{Study of mechanical properties of various samples}

2.6a Tensile strength test: The tensile strength test was conducted on ASTM made Computerized Universal Test- 
ing Machine (HOUNSFIELD H25KS). The sample of $100 \mathrm{~mm}$ length was clamped into the two jaws of the machine. Each end of the jaws covered $20 \mathrm{~mm}$ of the sample. Tensile strength was deliberated over the rest of $60 \mathrm{~mm}$ gauze length. Reading of the tensile strength test instrument for Newton force and extension was initially set to zero. The test was conducted at the constant strain rate of the order of $10 \mathrm{~mm} / \mathrm{min}$. Tensile stress was applied till the failure of the sample and loadextension curve was obtained. Each sample was tested seven times.

2.6b Compressive strength test: Compression strength of samples was also performed on ASTM made Computerized Universal Testing Machine (HOUNSFIELD $\mathrm{H} 25 \mathrm{KS}$ ). Composite sample was held between the two platforms and the strain rate was fixed at $10 \mathrm{~mm} / \mathrm{min}$ whereas the total compression range was $7.5 \mathrm{~mm}$. The compression stress was applied till the failure of sample. Total compression per unit force was noted.

2.6c Flexural strength test: Flexural strength of samples was also tested on Computerized Universal Testing Machine. The three-point bend flexural test was conducted in accordance with standard ASTM D method.

2.6d Wear test: The wear test of the testing sample was conducted according to Wear \& Friction Monitor (DUCOM-TR-20L). The disc was cleaned with emery paper and it was fixed at $500 \mathrm{rpm}$. The inner diameter of steel disc was $80 \mathrm{~mm}$. Initial weight of the sample was noted and the sample pin was fixed in the jaws of wear testing machine. Then machine was set to display zero wear and friction. The samples were then tested with different loads varying from $1-3 \mathrm{~kg}$. For each load the machine was allowed to run for $15 \mathrm{~min}$ and the readings were recorded. After $15 \mathrm{~min}$ the sample was taken out from the machine and weighed again. The loss in weight due to abrasion was calculated and this weight loss was used as the measure of wear.

\subsection{Thermal and morphological studies}

Thermal analysis of materials gives us information about their thermal stability. The thermal analysis comprises of various methods such as thermogravimetric analysis (TGA)/differential thermal analysis (DTA), derivative thermogravimetry (DTG) etc. Thermogravimetric analysis (TGA) and differential thermal analysis (DTA) studies of samples were carried out in nitrogen atmosphere on a thermal analyser at a heating rate of $10^{\circ} \mathrm{C} / \mathrm{min}$. Morphological analysis of different samples was carried out by studying SEM micrographs. These SEM micrographs of the samples give us information about the morphology of the resin and its respective biocomposite. These micrographs clearly show the difference between loaded and unloaded matrix.

\section{Results and discussion}

Evaluation of mechanical properties of natural fibre reinforced composite materials is an important tool in the study of the behaviour of these composite materials. It has been proved to be an efficient method in studying the behaviour of the materials under various conditions of tension, compression of fibre reinforced composites and its role in determining the mechanical properties. Mechanical properties of natural fibre reinforced composites principally depend on the (i) nature of the matrix material and (ii) distribution and orientation of the reinforcing fibres.

\subsection{Optimization of urea-formaldehyde resin}

Optimization of urea-formaldehyde resin has been done by evaluating optimal mechanical properties such as tensile strength, compressive strength, wear resistance etc (Singha and Thakur 2008b). In case of tensile strength test it has been observed that U-F samples of ratio $1: 2.5$ bear more load at a particular applied load as compared to samples of other ratios. This ratio $(1: 2 \cdot 5)$ could bear a load of $128.125 \mathrm{NF}$ with an extension of $1.84 \mathrm{~mm}$ as shown in figure $2 \mathrm{~A}$. On the other hand, samples of other ratios bear low loads. In compressive strength test it is evident from figure $2 \mathrm{~B}$ that the samples of ratio $1: 2.5$ could bear a load of $991 \mathrm{~N}$ at a compression of $3.51 \mathrm{~mm}$ while samples of other ratios bear fewer loads. It is evident from figure $2 \mathrm{C}$ that the samples of ratio $1: 2.5$ could bear a maximum load of $59 \mathrm{~N}$ at a deflection of $0.776 \mathrm{~mm}$.

In wear resistance test it has been observed that it is clear that the wear rate of samples of ratio $1: 2.5$ was less as compared to any other samples (figure 1C). Loss of material was due to abrasion and friction of samples with disc.

\subsection{Effect of reinforcement on mechanical properties of $U-F$ based biocomposites}

3.2a Tensile strength: It has been observed that composites with particle reinforcement showed more tensile strength which was followed by short fibre and long fibre reinforced composites (figures $3 \mathrm{~A}-\mathrm{C}$ ). It is clear from figures $3 \mathrm{~A}-\mathrm{C}$ that the samples of (i) particle reinforced composite could bear a load of $244.5 \mathrm{~N}$ at an extension of $1.91 \mathrm{~mm}$, (ii) short fibre reinforced composite could bear a load of $200.5 \mathrm{~N}$ at an extension of $1.95 \mathrm{~mm}$ and (iii) long fibres reinforced composite could bear a load of $191.5 \mathrm{~N}$ at an extension of $1.97 \mathrm{~mm}$. 

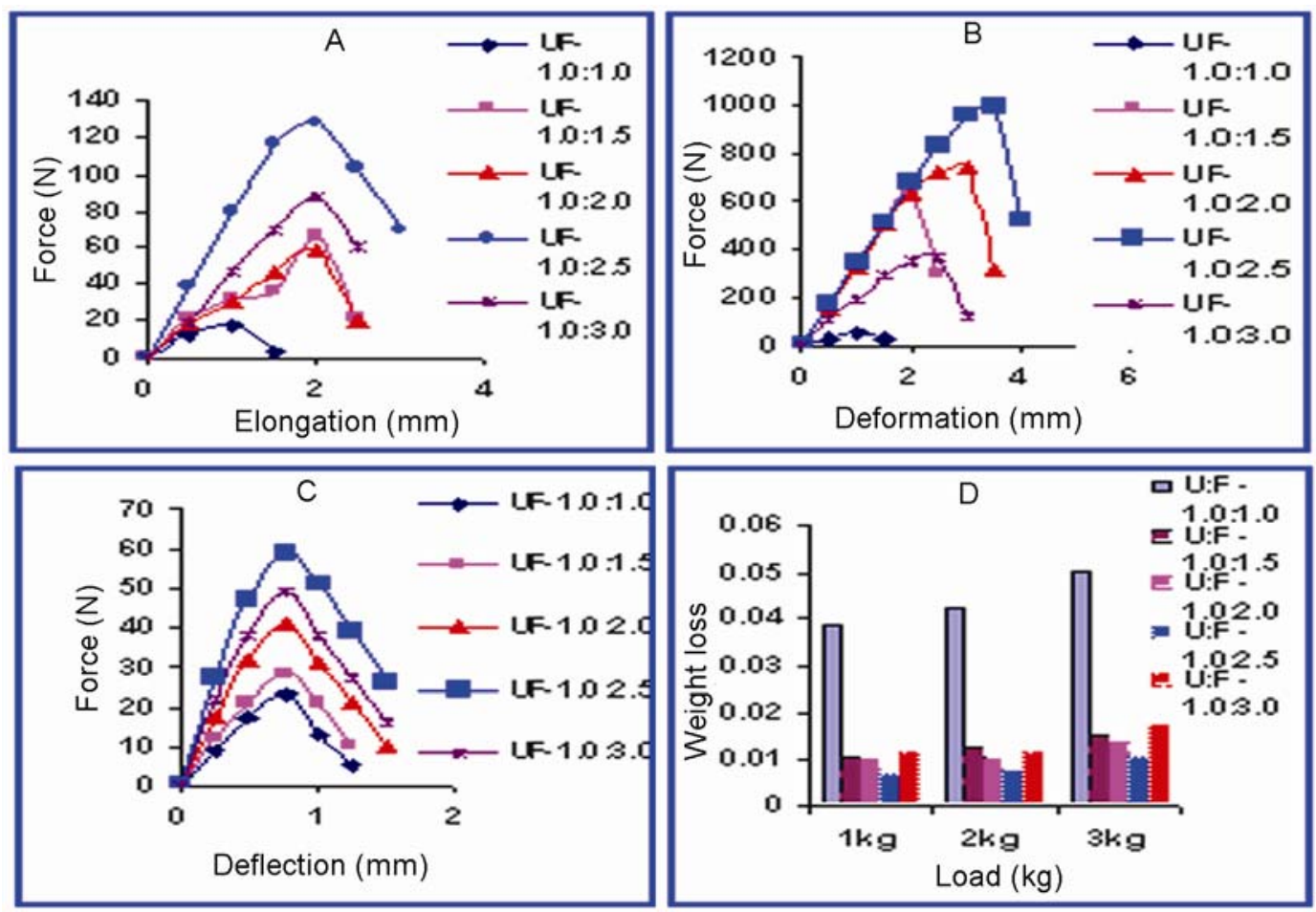

Figure 2. Tensile/compression strength/flexural strength and wear resistance curve of UF resin $(\mathbf{A}, \mathbf{B}, \mathbf{C}$ and $\mathbf{D})$
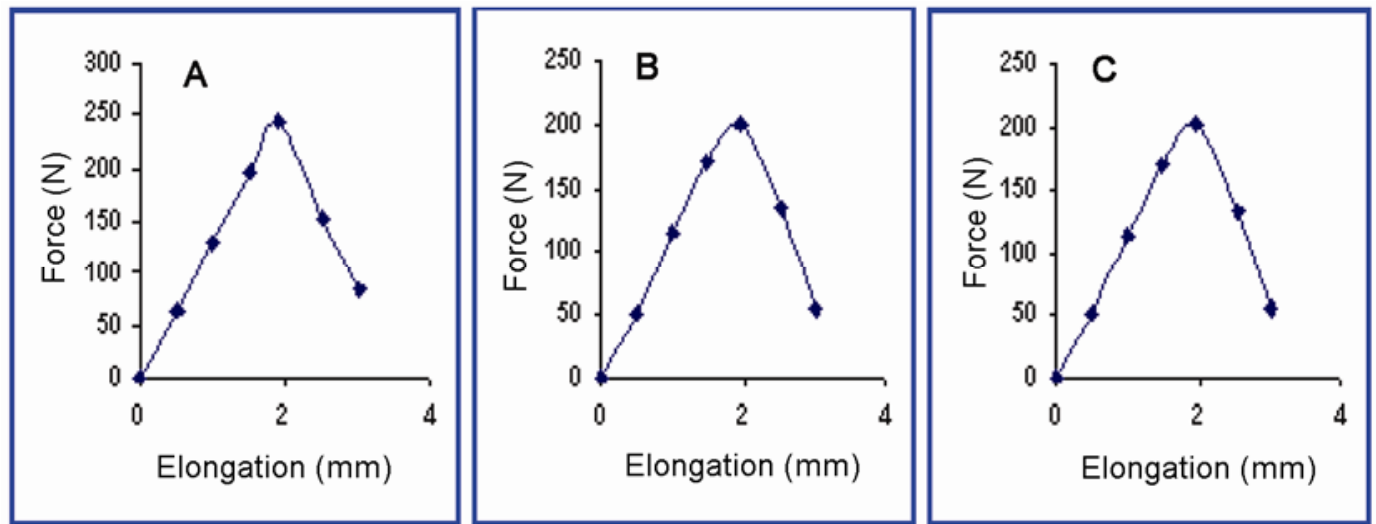

Figure 3. Tensile strength curves of $\mathrm{P}-\mathrm{Rnf} / \mathrm{SF}-\mathrm{Rnf}$ and LF-Rnf composites (A, B and $\mathbf{C})$.

$3.2 \mathrm{~b}$ Compressive strength: Compressive strength of UF resin matrix has been found to increase when reinforced with Pine needles. It has been found that with particle reinforcement, compressive strength increases to a much more extent than short and long fibre reinforcement (figures $4 \mathrm{~A}-\mathrm{C}$ ). It is clear that the samples of (i) particle reinforced composite could bear a load of $1895.5 \mathrm{~N}$ with a compression of $3.51 \mathrm{~mm}$, (ii) short fibre reinforced composite could bear a load of $1775 \mathrm{~N}$ with a compression of $3.53 \mathrm{~mm}$ and (iii) long fibre reinforced composite could bear a load of $1685 \mathrm{~N}$ with a compression of $3.586 \mathrm{~mm}$ 3.2c Flexural strength: Flexural strength of Pine needles reinforced composites also follows the same trend as in case of tensile and compressive strength. It is clear from figures $5 \mathrm{~A}-\mathrm{C}$ that the samples of (i) particle reinforced composite could bear a load of $107 \mathrm{~N}$ with a compression of $1.23 \mathrm{~mm}$, (ii) short fibre reinforced composite could bear a load of $80 \mathrm{~N}$ with a compression of $1.24 \mathrm{~mm}$ and (iii) long fibre reinforced composite could bear a load of $60 \mathrm{~N}$ with a compression of $1.25 \mathrm{~mm}$, respectively.

3.2d Wear test: As evident from figures 6A-C wear rate of UF matrix decreases appreciably when it is 

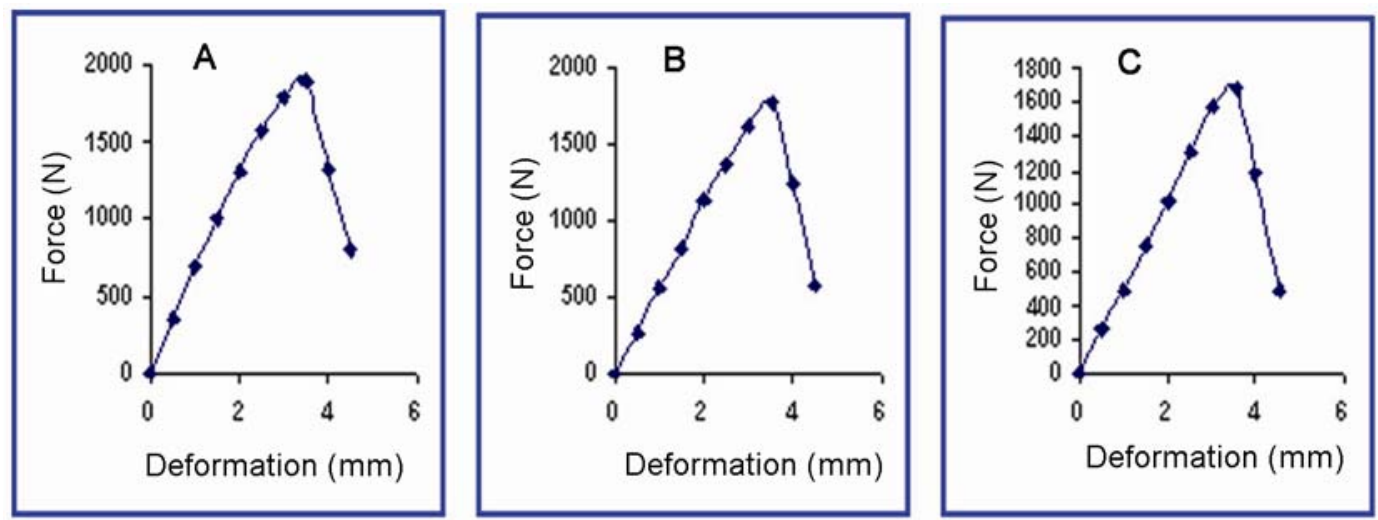

Figure 4. Compressive strength curves of $\mathrm{P}-\mathrm{Rnf} / \mathrm{SF}-\mathrm{Rnf}$ and $\mathrm{LF}-\mathrm{Rnf}$ composites $(\mathbf{A}, \mathbf{B}$ and $\mathbf{C})$.
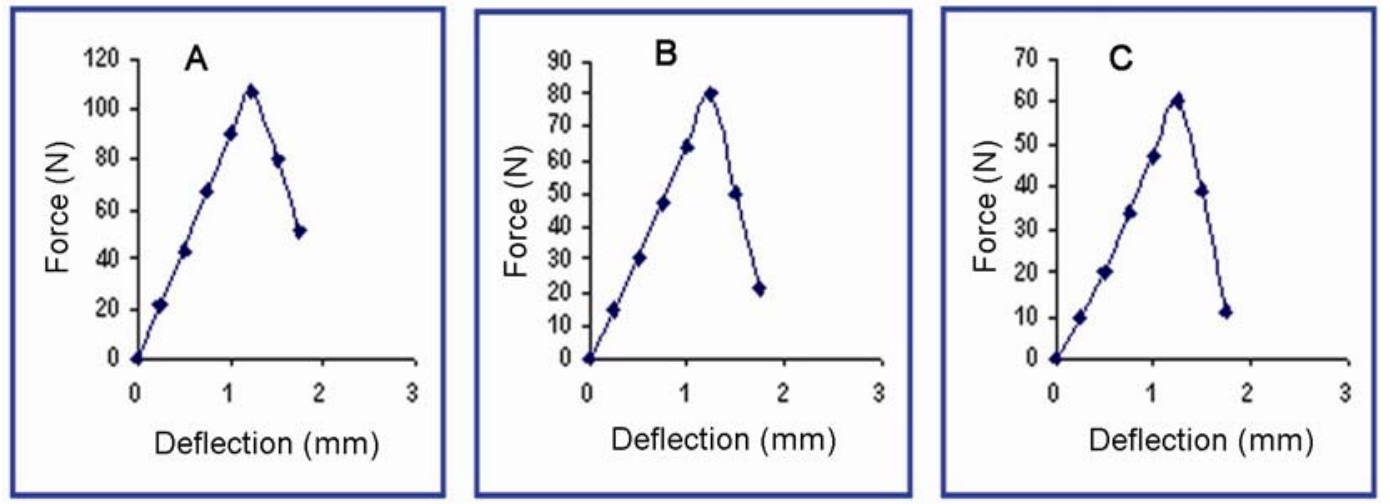

Figure 5. Flexural strength curves of $\mathrm{P}-\mathrm{Rnf} / \mathrm{SF}-\mathrm{Rnf}$ and LF-Rnf composites (A, B and $\mathbf{C})$.
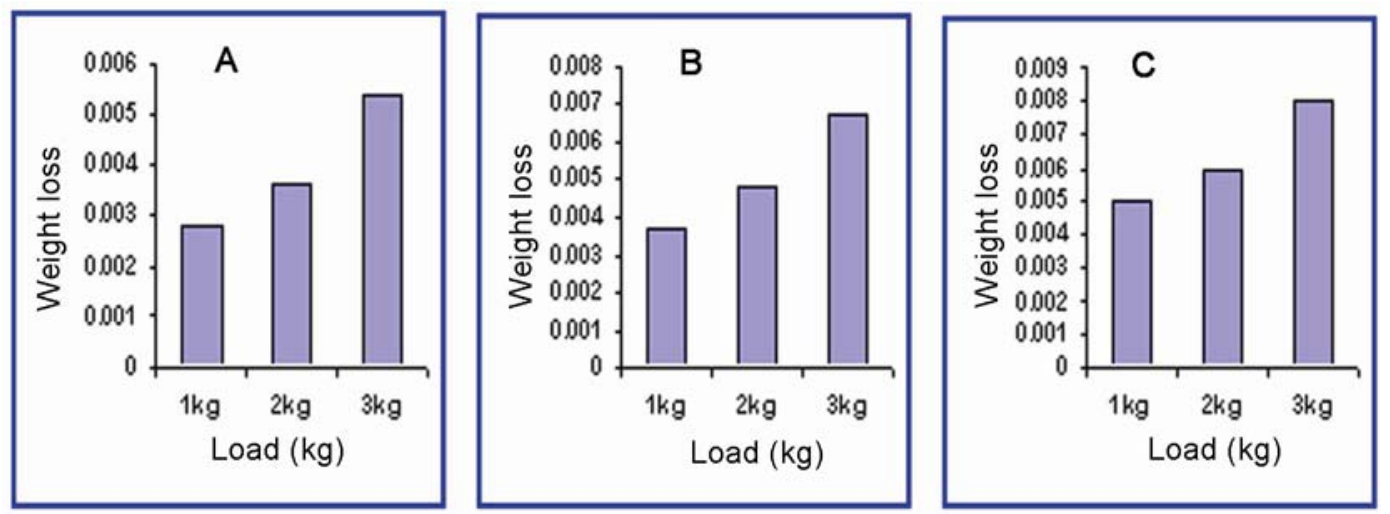

Figure 6. Wear resistance curves of P-Rnf/SF-Rnf and LF-Rnf composites (A, B and C).

reinforced with Pine needles. It has been observed that particle reinforcement decreases the wear rate to a much more extent than short and long fibre reinforcements.

From these results it is clear that these Pine needles are efficient candidates as reinforcing materials in UF matrix based composites. This may be due to larger surface area and more fibre/matrix interaction in case of Pine needles reinforced polymer composites. Good interfacial strength between the fibre and matrix is the most essential factor for achieving good fibre reinforcement. The interfacial strength depends on the surface topology of the fibre. The interface, therefore, plays a key role in controlling the mechanical properties of a composite. Interfacial bonding is a result of good wetting of the fibres by the UF matrix 

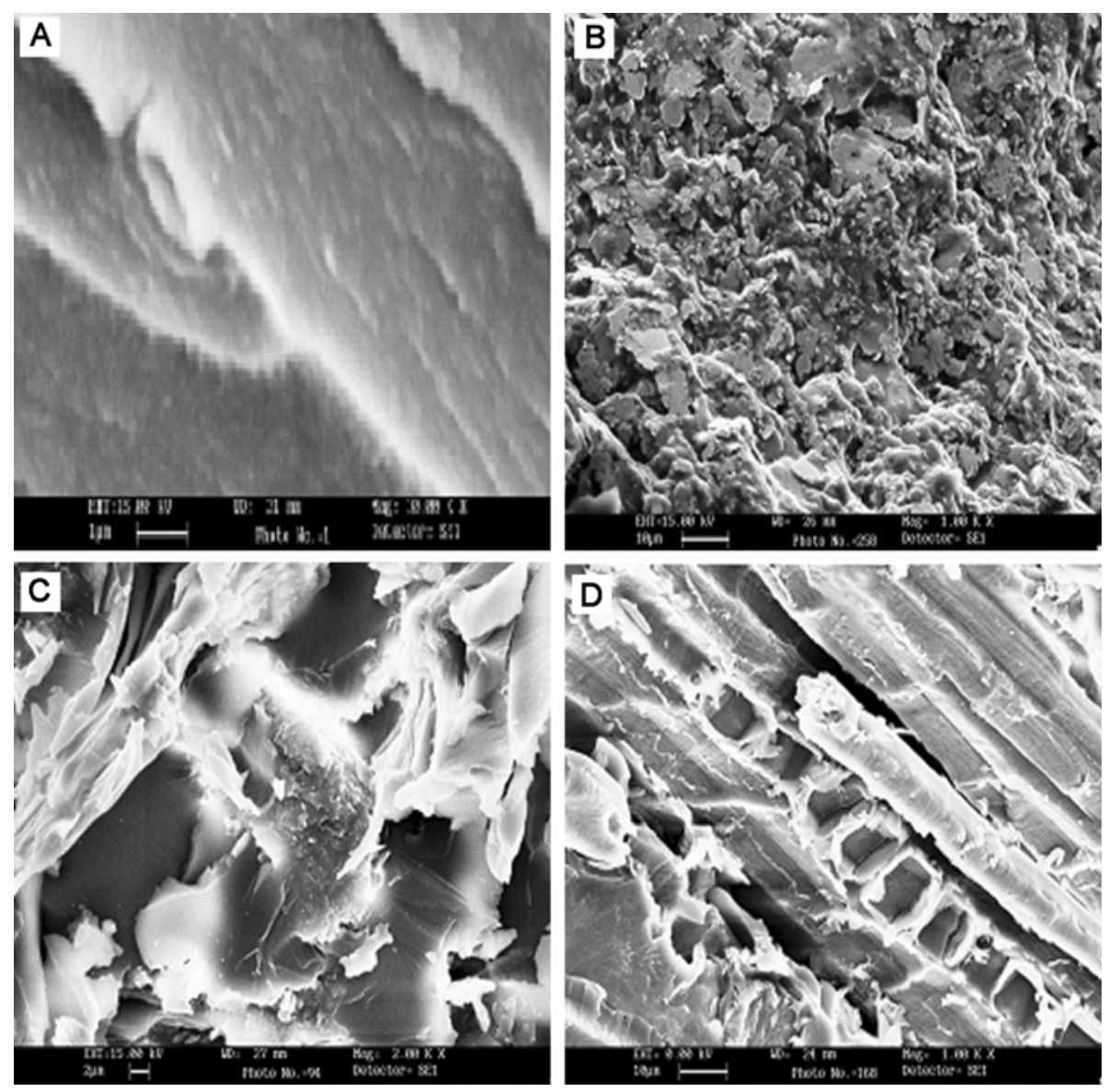

Figure 7. SEM images of UF resin, P-Rnf, SF-Rnf and LF-Rnf composites (A, B, C and $\mathbf{D})$.

Table 1. Thermogravimetric analysis of UF, PN and P-Rnf-UF composite.

\begin{tabular}{llccccc}
\hline Sr. no. & Sample code & IDT $\left({ }^{\circ} \mathrm{C}\right)$ & \% wt. loss & FDT $\left({ }^{\circ} \mathrm{C}\right)$ & $\%$ wt. loss & Final residue $(\%)$ \\
\hline 1 & PN & 223 & 23.45 & 507 & 64.44 & $35 \cdot 66$ \\
2 & U-F resin & 238 & 22.48 & 993 & 87.51 & $12 \cdot 49$ \\
3 & P-rnf-UF & 235 & 27.51 & 805 & 69.63 & $29 \cdot 37$ \\
\hline
\end{tabular}

UF, Urea formaldehyde resin; PN, pine needles; P-Rnf, particle reinforced composite.

Table 2. Differential thermal analysis of UF, PN and P-Rnf-UF composites.

\begin{tabular}{lll}
\hline Sr. no. & Sample code & \multicolumn{1}{c}{ Exothermic/endothermic peaks, ${ }^{\circ} \mathrm{C}(\mu \mathrm{V})$} \\
\hline 1 & PN & $333 \cdot 2(10 \cdot 3) ; 478 \cdot 1(29 \cdot 9)$ \\
2 & U-F resin & $179(6 \cdot 8) ; 253(5 \cdot 7) ; 271(27 \cdot 9) ; 545(9 \cdot 4) ; 725(-23 \cdot 0)$ \\
3 & P-Rnf-UF & $83(2 \cdot 7) ; 269(23)$ \\
\hline
\end{tabular}

UF, Urea formaldehyde resin; PN, pine needles; P-Rnf, particle reinforced composite.

as well as the formation of a chemical bond between the fibre surface and the UF matrix. From the results obtained above we can conclude that different degrees of reinforcement effects are achieved by the addition of Pine needles to UF matrix based polymer. This may be due to the different adhesion strengths between matrices and fibres. Particle reinforced composites show higher strength due to larger surface area and more fibre/matrix interaction.

\subsection{Morphological and thermal studies of biocomposites}

Morphological results obtained from SEM micrographs (figures 7A-D) clearly demonstrate that there is proper intimate mixing of fibre with the resin in the composites thus synthesized. It is clear from the micrographs that there is uniform mixing with particle reinforcement as compared to short and long fibre reinforcements. Thermo- 
gravimetric analysis (TGA) of Pine needles, polymeric UF resin and composites was investigated as a function of $\%$ weight loss with the increase in temperature. In case of raw fibre, in the beginning depolymerization, dehydration and glucosan formation took place between the temperature ranges of 26 and $195^{\circ} \mathrm{C}$ followed by the cleavage of $\mathrm{C}-\mathrm{H}, \mathrm{C}-\mathrm{C}$ and $\mathrm{C}-\mathrm{O}$ bonds. The initial decomposition temperature (IDT) for pine needles has been found to be $223^{\circ} \mathrm{C}$ and the final decomposition temperature (FDT) to be $507^{\circ} \mathrm{C}$ as shown in table 1 . On the other hand, in case of UF resin it is single stage decomposition and the observed initial decomposition temperature is $238^{\circ} \mathrm{C}$ and the final decomposition of the resin took place at $993^{\circ} \mathrm{C}$ (table 1). It has been observed that for composites initial decomposition temperature is $235^{\circ} \mathrm{C}$ and the final decomposition of the composite took place at $805^{\circ} \mathrm{C}$ (table 1). These results are further supported by differential thermal analysis (table 2). These values are between the degradation temperatures observed for matrix and fibre. This indicates that the presence of cellulose fibres affects the degradation process of the biocomposites. These results are consistent with the results reported earlier (Singha and Thakur 2008b).

\section{Conclusions}

Mechanical properties of randomly oriented intimately mixed Pine needle reinforced UF composites were investigated with special reference to the size of the fibre. Various test methods were used for complete mechanical characterization of natural fibre reinforced composites. In case of mechanical behaviour, particle reinforcement of the UF resin has been found to be more effective as compared to short and long fibre reinforcement. The mechanical behaviour has been strongly supported by the SEM analysis. Finally, it can be concluded that by utilizing Pine needle, we can synthesize cost-effective and ecofriendly composite materials possessing suitable mechanical properties and this waste biomass can be a potential candidate for reinforcement in polymer composites.

\section{Acknowledgements}

We express our sincere thanks to the Director, National Institute of Technology, Hamirpur, for providing basic laboratory facilities. Financial assistance provided by the University Grants Commission, New Delhi, through grant no. F. No. 30-80/2004 (SR) is highly acknowledged.

\section{References}

Bledzki A K and Gassan J 1999 Prog. Polym. Sci. 24221

Chakraborty A, Sain M and Kortschot M 2006 ACS Symp. Series 938169

Chauhan G S, Bhatt S S, Kaur I, Singha A S and Kaith B S 2000 J. Polym. Degrad. \& Stab. 69261

Chauhan G S, Lal H, Singha A S and Kaith B S 2001 Indian J. Fibre \& Textile Res. 26302

Gassan J and Bledzki A K 1997 Compos. Part A-Appl. Sci. 28 1001

Hornsby P R, Hinrichsen E and Tarverdi K 1997 J. Mater. Sci. 321009

Joshi S V, Drzal L T, Mohanty A K and Arora S 2004 Composites: Part A 35371

Kaith B S and Kalia Susheel 2007 Int. J. Polym. Anal. \& Charact. 12401

Kaith B S, Singha A S and Kumar Kalia Susheel 2007 AUTEX Res. J. 7119

Mao L, Imam S, Gordon S, Cinelli P and Chiellini E 2000 J. Polym. Environ. 8205

Mathew L, Joseph K U and Joseph R 2006 Bull. Mater. Sci. 29 91

Majumdar S and Adhikari B 2005 Bull. Mater. Sci. 28703

Misra B N, Kaur I, Gupta A, John V and Singha A S 1996 Polym. Compos. 4411

Nakagaito A N and Yano H 2004 Appl. Phys. A-Mater. 78 547

Nakagaito A N and Yano H 2005 Appl. Phys. A-Mater. 80 155

Panthapulakkal S, Zereshkian A and Sain M 2006 Bioresource Technol. 97265

Ray D, Sarkar B K, Rana A K and Bose N R 2001 Bull. Mater. Sci. 24129

Singha A S and Thakur Vijay K 2008a E-J. Chem. 5782

Singha A S and Thakur Vijay K 2008b Bull. Mater. Sci. 31 791

Singha A S, Kaith B S and Sarwade B D 2002 Hung. J. Ind. Chem. VESZPREM 30289

Singha A S, Kaith B S, Chauhan Ashish and Misra B N 2006 J. Polym. Mater. 233456

Singha A S, Shama Anjali and Thakur Vijay K 2008a Bull. Mater. Sci. 311

Singha A S, Shama Anjali and Misra BN 2008b J. Polym. Mater. 2591 